\title{
Roh di Endor: Pemanggilan Roh dalam 1 Samuel 28:1-25 dan Ajaran Aliran Pangestu
}

\author{
Alentinus Yonathan
}

\begin{abstract}
Abstrak
Penelitian ini menelusuri ajaran dalam 1 Sam. 28 yang terkait dengan pemanggilan roh orang mati dan membandingkan dengan ajaran Aliran Pangestu mengenai hal itu. Hasil penelitian pada konteks kitab Samuel menunjukkan bahwa roh yang muncul di Endor adalah bukan roh Samuel, sedangkan dalam ajaran Pengestu mengenai kematian juga dapat disimpulkan bahwa, roh di Endor juga bukanlah roh Samuel karena roh Samuel sudah menyatu atau lebur dengan Allah. Hasilnya dapat dipergunakan dalam proses kontekstualisasi bagi orang-orang Pangestu yang telah menjadi warga Gereja Kristen namun masih diwarnai pandangan lama mereka.

Kata Kunci: Pemanggilan roh, dunia orang mati, teologi Deuteronomis, Roh Allah, Suksma Sejati.
\end{abstract}

\begin{abstract}
This article explores the teaching in 1 Samuel 28 about the summon of the spirit in comparison with the teaching of Pangestu Beliefs concerning the issue. Based on analysis of the historical context of the Book of Samuel, the result shows that the spirit in Endor is not that of Samuel while based on the teaching of Pangestu about death, the spirit in Endor is not the spirit of Samuel either because his spirit has merged in Divine Union. The result of this study can be used in contextualization process for the Pangestu adherents who have joined Christian church but still cling to their old-world view.
\end{abstract}

\section{Pendahuluan}

Menurut Ludji Kitab Samuel adalah lanjutan Sejarah Deuteronomis, dalam tulisannya terdapat skema yang menjelaskan tentang doa, hukuman, pertobatan dan keselamatan. ${ }^{218}$ Terlihat juga dari bahasa dan cara berpikirnya sangat mirip dalam

218 Barnabas Ludji, Pemahaman Dasar Perjanjian Lama: Untuk Studi Kritis, Jilid 1 (Bandung: Bina Media Informasi: 2009), 156. 
hukum Deuteronomi (Kitab Ulangan). ${ }^{219}$ Dengan demikian, dapat dipastikan bahwa Kitab Yosua sampai dengan Raja-raja meneruskan garis pemikiran teologi Kitab Ulangan. ${ }^{220}$ Pemahaman ini dipertegas dengan pandangan bahwa Kitab Samuel diwarnai teologi Kitab Ulangan, sebab kedua kitab menekankan keesaan Allah.

Dalam buku Sejarah Israel yang ditulis Hinson dinyatakan,221 “Orang-orang Yahudi di pembuangan pasti sudah mengenal ajaran kepada orang-orang Israel bahwa kurban-kurban persembahan hanya dapat dipersembahkan di Yerusalem, dan menyebabkan orang-orang Yahudi di Babilonia menjadi yakin bahwa kurban-kurban persembahan tidak dapat lagi dilakukan dalam ibadah mereka selama di Babilonia. Pengajaran dalam Kitab Ulangan mengenai Allah dan jalan-jalan-Nya, mengobarkan kembali semangat orang-orang Yahudi di pembuangan. Kemudian perintah-perintah seperti pada Ulangan 6:4-9 menjadi penting sekali bagi mereka." ${ }^{222}$ Shema Yisrael Yahwe Elohenu Yahwe Ehad, yang berarti “Dengarlah hai Israel, Yahwe itu Allah kita, Yahwe itu satu" (Ul. 6:4).

Mengenai dunia orang mati dan pemanggilan roh, di masa itu ada dua ajaran. Pertama dari orang Israel, dan kemudian dari bangsa-bangsa sekitar. Dalam konteks Israel kuno, sudah ada praktik atau kegiatan yang berhubungan dengan dunia roh atau dunia orang mati. "Ritual pemanggilan dan bertanya kepada orang mati, meminta nasihat atau dukungan pada si arwah (Ul. 18:11; Im. 19:31; 20:6, 27; Yes. 8:19; 65:4; 1 Sam. 28), dan tentang persembahan kepada orang mati (Ul. 26:14), hal ini menunjukkan fakta bahwa "Israel" dan Yehuda diperkirakan juga menerima dan bahkan melakukan praktikpraktik mengenai dunia orang mati pada masa sebelum pembuangan." ${ }^{223}$ Kemudian Nekromansi ${ }^{224}$ adalah bagian dari agama rakyat pada masa itu.

${ }^{219}$ Marthin Noth, The Deuteronomistic History, Journal for the Study of the Old Testament Supplement Series 15, Second Edition (Sheffield: JSOT Press, 1981), 17.

${ }^{220}$ Barnabas Ludji, Pemahaman Dasar Perjanjian Lama: Untuk Studi Kritis, Jilid, 115.

221 David F. Hinson, Sejarah Israel: Pada Zaman Alkitab, penerj. Marthinus Theodorus Mawene (Jakarta: BPK Gunung Mulia, 2015), 201.

222 Tafsiran Ulangan 6:4-5 "Tujuan teks ini ialah untuk menganjurkan ketaatan kepada sebuah hukum khusus: Larangan untuk beribadat kepada ilah selain Allah. Orang-orang Israel bersiap-siap untuk masuk ke tanahyang sangat subur." Dianne Bergant dan Robert J. Karris, ed., Tafsir Alkitab Perjanjian Lama, penerj. A.S. Hadiwijaya (Yogyakarta: Kanisius, 2002), 204-205.

223 Jan Christian Gertz, dkk., Purwa Pustaka: Eksplorasi ke dalam Kitab-kitab Perjanjian Lama dan Deuterokanonika, penerj. Robert Setio dan Atdi Susanto (Jakarta: BPK Gunung Mulia, 2017), 107.

${ }^{224}$ Ritual pemanggilan: berarti memanggil orang mati dari dunia bawah. Jan Christian Gertz, dkk., Purwa Pustaka: Eksplorasi ke dalam Kitab-kitab Perjanjian Lama dan Deuterokanonika, penerj. Robert Setio dan Atdi Susanto, 107. 
Ajaran mengenai dunia orang mati dan pemanggilan roh juga hadir di tengah penganut berbagai agama di Indonesia. Menurut ajaran Kejawen secara umum:

1. Badan jasmani telah suci, terbawa dalam keadaan nyata. Dapat memulai hidup yang sempurna abadi selamanya, di dunia hidup begitupun di dalam akhirat juga hidup. Apa yang dikehendaki semua ada di sana. Tetapi kematian seperti ini, dapat terpenuhi jika dalam hidupnya bersikap seperti Para Wali dan $\mathrm{Nabi}^{225}$

2. Ada roh-roh lain di dalam kenyataan seperti, Merkayangan, kehidupan seperti manusia biasa tetapi tidak ada terang. Jin-Siluman, makhluk halus yang tinggal di tempat berair. Serpo Bongso-penguasa Rawa Pening, adanya siluman yang berada di danau besar ini. Kajiman, mereka yang hidup di rumah-rumah kuno. Demit, bangsa yang tinggal di daerah pegunungan dan sejuk hawanya. ${ }^{226}$

3. Dalam Kejawen hanya terdapat tradisi yang dinamakan ruwatan. Yaitu kepercayaan terhadap keberadaan nenek moyang, menyatu terhadap kekuatan alam yang mempunyai pengaruh terhadap kehidupan manusia. Kegiatan ini menggunakan wayang dan sesajen lain dalam ritualnya. ${ }^{227}$

Di Indonesia, banyak orang yang berlatar belakang Kejawen menjadi pemeluk agama Islam atau Kristen karena, Kejawen baru diakui legalitasnya di tahun 2017 oleh Mahkamah Agung setelah sekian dekade dianggap bukan sebagai agama atau keyakinan. Namun, ketika menjadi Kristen tidak kecil kemungkinan ajaran Kejawen masih mewarnai pola pandang dan iman mereka. Bagaimana kiranya bila ajaran mengenai pemanggilan roh yang diajarkan oleh Kitab Samuel dibandingkan dengan ajaran aliran Pangestu yang mungkin masih mempengaruhi orang-orang penganut Kejawen yang telah menjadi Kristen?

\section{Kajian}

1. 1 Samuel 28:1-25

\footnotetext{
${ }^{225}$ https://www.academia.edu/36332977/KEJAWEN, hal. 24 diakses 24 Agustus 2020.

226 https://www.academia.edu/36332977/KEJAWEN, hal. 26-27 diakses 24 Agustus 2020.

227 https://www.academia.edu/36332977/KEJAWEN, hal. 48-50 diakses 24 Agustus 2020.
} 
Ketika bangsa Israel memasuki tanah Kanaan, mereka mengambil alih kuilkuil menjadikannya tempat untuk menyembah Yahwe, namun mereka cenderung melihat Yahwe seperti Baal, sehingga seolah-olah ada banyak Yahwe. Kata-kata pengakuan kepercayaan orang Israel merupakan protes terhadap "divergensi" pembedaan itu: "Yahwe itu satu". 228

Dengan demikian, di Israel dimunculkan suatu teologi yang menekankan bahwa Allah tidak dapat dipandang secara "politeis." Artinya sebagai salah satu "Allah". Israel diajak mengenali Allah Israel yang "monoteis". Hal demikian juga kembali disuarakan agar bangsa Israel yang dideportasi, terhindar dari keinginan untuk menyembah dewa-dewa Babilonia, dan tetap setia kepada Allah yang Esa.

Dalam literatur hikmat yaitu terdapat dalam Pengkhotbah dan Ayub ditekankan bahwa orang mati tidak mengetahui apapun, dan oleh sebab itu percuma saja meminta nasehat kepada mereka (Pkh. 9: 4-6, 10; Ayb. 14:21). Teks-teks seperti itu sangat perlu diajarkan pada periode kehidupan di Israel pada periode itu, karena keyakinan-keyakinan yang berlaku secara luas di Timur Tengah Kuno berpotensi memberi pengaruh yang kuat. ${ }^{229}$ Diajarkan dalam keyakinan-keyakinan itu bahwa, setelah kematian, dimakamkan, dan terjadi pembusukan mayat, orang mati akan tinggal di dunia bawah, dunia bawah yang berdebu dan gelap (dalam bahasa Ibrani sering disebut sheol). ${ }^{230}$

Jadi, pada masa Pembuangan ke Babilonia, selalu ditekankan mengenai keesaan Allah dan kedaulatan Allah sebagai yang tunggal. Hal ini berarti tidak ada kuasa lain yang dapat berperan atau berpengaruh. Penekanan ajaran mengenai Allah yang esa ini, akan menjelaskan makna narasi mengenai kemunculan roh di Endor.

${ }^{228}$ J. Blommendal, Pengantar Kepada Perjanjian Lama, penerj. P.S. Naipospos (Jakarta: BPK Gunung Mulia, 2013), 60.

229 Jan Christian Gertz, dkk., Purwa Pustaka: Eksplorasi ke dalam Kitab-kitab Perjanjian Lama dan Deuterokanonika, penerj. Robert Setio dan Atdi Susanto, 107-108.

230 Jan Christian Gertz, dkk., Purwa Pustaka: Eksplorasi ke dalam Kitab-kitab Perjanjian Lama dan Deuterokanonika, penerj. Robert Setio dan Atdi Susanto, 108. 
Kemunculan roh di Endor dapat ditafsirkan sebagai datangnya roh Samuel sendiri. Tafsiran ini memiliki dasar bahwa Samuel yang telah mati memiliki akses untuk mengenal apa yang sedang terjadi di dunia. Kemudian, dapat ditafsirkan bahwa, ia dapat merespons manusia yang masih ada di dunia. Tafsiran ini juga dapat berdasarkan logika bahwa, sang pemanggil roh memang memiliki kuasa atau kemampuan membuat roh orang mati menuruti panggilannya. Pilihan tafsiran kedua adalah roh yang muncul di sana adalah roh Allah sendiri karena, Ia memang berkuasa melakukan apa saja.

Namun, dengan konteks yang sudah dijelaskan di atas, di mana tekanan pada keesaan Allah menjadi utama, maka harus disimpulkan bahwa, dalam Kitab 1 Samuel 28:1-25 roh yang muncul di Endor adalah Allah. Pertama, hal ini disebabkan karena pada konteks kitab Samuel, ditekankan Ia-lah yang satusatunya berkuasa atas apapun dan lingkup alam kehidupan dan alam maut. Akan sangat mengejutkan jika orang tidak memahami bahwa kekuasan Allah tidak mencakup atau melingkupi sampai pada dunia orang mati.

Kedua, dipahami bahwa orang yang telah mati terpisah dari TUHAN (Mzm. 88:6), dan tidak dapat berkomunikasi dengan-Nya (Yes. 38:18; dan Maz. 88: 6, 11-13). ${ }^{231}$ Kondisi orang yang telah mati, berada di tempat yang hening atau gelap sehingga ketika berada di sana, orang yang sudah mati tidak mengerti apa yang telah terjadi di dunia. Dengan demikian cukup mengherankan jika roh Samuel ditafsirkan hadir dan memberikan nubuat atas Saul. Sebab dia sudah terpisah dengan dunia, dan tidak mengerti apa yang terjadi di dunia atau sudah berada di sheol.

Jadi dapat disimpulkan, dalam konteks narasi yaitu kitab Samuel masa itu, maka kesimpulan yang masuk akal adalah kemungkinan roh Allah sendirilah yang muncul di Endor. Bila tidak demikian ajaran yang terkandung di buku Samuel tersebut, maka konsekuensinya adalah kitab itu memberikan tempat begitu besar pada kuasa dan peran seorang pemanggil roh. Keyakinan akan 
kuasa dan peran pemanggil roh itu adalah suatu kepercayaan bangsa-bangsa lain di sekitar Israel yang justru dalam teologi yang dikenal dengan nama teologi Deuteronomis justru ditentang habis-habisan.

2. Aliran Pangestu:

Pangestu, singkatan dari "Paguyuban Ngesti Tunggal", berarti "persatuan untuk dapat tunggal.” Aliran ini didirikan pada 20 Mei 1949, di Surakarta. Akan tetapi ajaran pangestu, seperti yang diuraikan di dalam Serat Sasangka Jati, sudah diwahyukan pada 14 Februari 1932 kepada R. Soenarto Mertowerjodo. ${ }^{232}$ Sejak kecil ia sudah gemar mencari jalan benar tuntunan ilahi dengan mencari banyak guru dan segala nasehat gurunya ditaati. Tapi semakin lama semakin kacau hatinya, sehingga pada akhirnya ia memutuskan untuk tidak berguru lagi. ${ }^{233}$ Berbagai-bagai laku telah ia jalani, misalnya: Tapa Kumkum, ialah berendam agar menerima wahyu. Ia juga pernah berjalan terus ke Utara pada malam hari sampai habis kekuatannya, lalu membakar menyan dan membaca mantera gurunya. Pernah ia harus bersemedi dengan jalan memandang dengan tidak berkedip kepada bayangannya sendiri di bawah terang bulan. Setelah mengucapkan mantera ia berhasil. Kemudian ia dilatih dengan bayangannya mengenai hal yang baik dan yang buruk. Tatkala hampir menguasai teknik dari laku tersebut, ia menghentikan latihannya karena menganggap berada di jalan yang sesat. 234

Setelah ia meninggalkan hal-hal yang berbau klenik itu, pada tanggal 14 Februari 1932, saat sore hari pukul 17:20 WIB, R. Soenarto melakukan sebuah perenungan. Ia memohon terang Tuhan, dilanjutkan solat daim. Pada saat keteduhannya itu ia mendapatkan wahyu ilahi, yang tiba dalam tiga tahap: Pertama, penegasan mengenai Ilmu Sejati itu adalah petunjuk nyata tentang jalan benar menuju asal dan tujuan hidup. Kedua, berupa penyertaan Sang Suksma Sejati tentang siapakah dirinya dan apakah tugasnya, serta siapakah Suksma Kawekas itu. Ketiga, berupa sabda yang meneguhkan hati R. Soenarto

${ }^{232}$ Harun Hadiwiyono, Kebatinan dan Injil, (Jakarta: BPK Gunung Mulia, 1987), 63.

${ }^{233}$ Harun Hadiwiyono, Kebatinan dan Injil, 63.

234 Sularso Sopater, Inti Ajaran Aliran Valentinian dan Inti Ajaran Aliran Pangestu: Suatu Pembandingan, (Bandung: Badan Media Informasi, 2011), 80. 
dalam perjalanan tugasnya menaburkan terang, serta janji akan diberikannya dua pembantu yaitu, Hardjoprakoso dan Soemodiharjo untuk mencatat sabdasabda Sang Suksma Sejati. Lalu pada 27 Mei 1932 malam, mereka mencatat sabda-sabda itu dan dikumpulkan menjadi Kitab Sasangka Jati. ${ }^{235}$ Di dalam kitab inilah, terdapat ajaran mengenai konsep orang mati.

Dalam budaya Jawa istilah Kejawen disebut sebagai agama penghayat. Penghayat ini sering disebut dengan kebatinan. Kata batin berasal dari bahasa Arab yang bermakna: Perut, rasa mendalam, tersembunyi, rohani, dan asasi. Batin itu mengarah kepada ilmu jiwa dan rohani yang menunjukkan sifat yang berada dalam dirinya sendiri sebagai pribadi yang benar. ${ }^{236}$ Inti ajarannya adalah bagaimana manusia lepas dari sesuatu yang semu dan mencoba lepas dari dinding alam persepsi untuk bersemayam pada realita sejati dari esensinya, yaitu roh. ${ }^{237} \mathrm{Hal}$ semacam ini sering disebut manunggaling kawula lan Gusti atau yang berarti menyatunya manusia dengan Allah. ${ }^{238}$ Dengan demikian paham seperti ini terdapat dalam setiap aliran kebatinan yang dianut oleh orang Jawa.

Menurut Harun Hadiwiyono, aliran Pangestu dipengaruhi oleh agama Kristen dalam jalan pemikirannya. ${ }^{239}$ Sebab dalam ajaran ini mengajarkan bahwa jiwa manusia yang sejati adalah Roh Suci, yang bersumber dari Tuhan Yang Maha Esa,240 seperti halnya dalam kekristenan adanya Roh Kudus yang juga merupakan bagian dari bentuk ketritunggalan Allah. Nama Pangestu merupakan singkatan dari Paguyuban Ngesti Tunggal, artinya perkumpulan mereka mencari Yang Tunggal. ${ }^{241}$ Kata Tunggal dapat ditafsirkan secara

235 Sularso Sopater, Inti Ajaran Aliran Valentinian dan Inti Ajaran Aliran Pangestu: Suatu Pembandingan, 80-81.

${ }^{236}$ Rahmat Subagya, Kepercayaan Kebatinan Kerohanian Kejiwaan dan Agama (Yogyakarta: Kanisius, 1995), 16.

${ }^{237}$ Rahmat Subagya, Kepercayaan Kebatinan Kerohanian Kejiwaan dan Agama, 16.

238 M. Suprihadi Sastrosupono, Sinkretisme dan Orang Kristen Jawa (Bandung: Lembaga Literatur Babtis, 1984), 23.

${ }^{239}$ Harun Hadiwiyono, Kebatinan dan Injil, 11.

${ }^{240}$ Muryana, Dialog Interreligius - Kultural dan Civil Religion Studi atas Pagutuban Ngesti Tunggal, Jurnal ESENSIA, Vol. XIV No. 2 (Yogyakarta: UIN Sunan Kalijaga, 2013), 212.

${ }^{241}$ S. De Jong, Salah Satu Sikap Hidup Orang Jawa (Yogyakarta: Kanisius, 1976), 16. 
horizontal maupun vertikal; mencari kesatuan (solidaritas) dengan golongangolongan lain di dalam masyarakat, begitu juga kesatuannya dengan Tuhan. ${ }^{242}$

Menurut aliran Pangestu ada beberapa macam kematian manusia. Hal ini dengan lugas dijelaskan oleh Sularso Sopater dalam disertasinya. ${ }^{243}$ Menurut Pangestu ada beberapa macam kematian manusia. Pertama, mati secara tidak sempurna, yaitu badan kasarnya rusak, tetapi badan halusnya atau jiwanya tetap hidup terus dan melayang-layang di dalam alam halus atau alam kafirula. Kedua, mati secara sempurna. Kesempurnaan mati ini "adalah tercapainya persatuan antara roh suci dengan Suksma Sejati, pada saat badan jasmaninya menghembuskan nafas penghabisan atau mati, alias siap untuk dikubur." Ketiga, manusia yang telah bertunggal dengan Sang Suksma Sejati, atau telah mencapai derajat sejati ketika ia masih hidup. Orang ini telah mencapai kesempurnaan hidup, dan disebut telah mati selama hidup.

\section{Antara 1 Samuel 28:1-25 dengan Ajaran Aliran Pangestu}

Apa pandangan aliran Pangestu mengenai Samuel? Secara narasi berita mengenai kematian Samuel dijelaskan pada 1 Sam. 28:3a "Adapun Samuel sudah mati. Seluruh orang Israel sudah meratapi dia dan mereka telah menguburkan dia di Rama, di kotanya...." Sesuai konsep orang mati dalam kehidupan Timur Tengah, bahwa Samuel telah berada dalam ketenangan di dunia bawah. Mereka meyakini bahwa kematian menandai akhir kehidupan di bumi, akan tetapi si orang mati akan tetap hidup di sheol, sebuah tempat berdebu dan dalam kegelapan. ${ }^{244}$ Namun, ketika sudah mati dan berada di sheol, mereka sudah tidak memiliki akses untuk hadir kambali di dunia. Bahkan, ketika orang sudah berada di sheol tidak dapat berhubungan kembali dengan Allah (Yes. 38:18), dan mereka terpisah dari Allah (Mzm. 88:6).

${ }^{242}$ S. De Jong, Salah Satu Sikap Hidup Orang Jawa, 16.

${ }^{243}$ Sularso Sopater, Inti Ajaran Aliran Valentinian dan Inti Ajaran Aliran Pangestu: Suatu Pembandingan, 139-140.

${ }^{244}$ Philip J. King dan Lawrence E. Stager, Kehidupan Orang Israel Alkitabiah, penerj. Robert Setio dan Atdi Susanto, (Jakarta: BPK Gunung Mulia, 2012), 428. 
Lalu bagaimana dengan paham ajaran aliran Pangestu yang memiliki tiga jenis kematian manusia mengenai Samuel? Seperti yang sudah dijelaskan di atas, adanya kematian tidak sempurna, kematian sempurna, dan orang yang telah manunggal dengan Sang Khalik walaupun masih hidup dalam dunia.

Samuel selama hidupnya telah menjadi abdi Allah yang setia. Telah menjadi hakim atas bangsa Israel, dan juga telah menjadi nabi yang bijaksana bagi Saul dan Daud. Dari sudut pandang Pangestu atau orang Kristen yang meyakini ajaran aliran Pangestu, maka dalam 1 Sam. 28:3a dipahami bahwa Samuel dikuburkan. Dengan demikian, orang mati badan kasarnya rusak dan busuk kemudian roh-nya berada dalam sheol sesuai dengan kepercayaan umat Israel. ${ }^{245}$ Dalam perjalanan pelayanannya, ia sebagai abdi Allah yang setia maka menurut ajaran Pangestu, Samuel telah manunggal dengan Allah selama hidupnya, kerena ia hidup suci.

Dalam konteks Israel kuno, ada istilah sheol sebagai dunia orang yang telah mati. Sheol bukanlah tempat penghukuman, dalam artian siksaan dan deraan; sebaliknya sheol menandakan keterbuangan dari Allah, yaitu tempat orang yang sudah mati menyesali segala kesalahannya ketika masih hidup. Dalam kepercayaan orang Israel, hakekat dari kehidupan adalah kemampuan untuk memuliakan Allah sehingga bagi orang yang sudah mati dan berada di sheol tidak dapat lagi memuliakan Allah, karena tidak memiliki kontak dengan Sang Ilahi. ${ }^{246}$

Demikian juga dalam ajaran aliran Pangestu mengenai dunia orang mati, yang disebut alam kafiruna. Di sana adalah tempat kesengsaraan, namun jika roh seorang manusia mau bertobat, kelak kesengsaraan akan mereda dan bahkan lenyap. Jika roh itu mau bertobat maka diberikan kesempatan melakukan reinkarnasi ke dalam dunia. Sepertinya aliran Pangestu meminjam pemahaman reinkarnasi dari agama Hindu, akan tetapi dalam Pangestu reinkarnasi dapat terjadi tujuh kali sesuai dengan lapisan alam kafiruna. ${ }^{247}$

245 Agustinus Faot, Jonathan Octavianus, dan Juanda, Kematian Bukan Akhir dari Segalanya, Jurnal Kerruso Vol. 2, No. 2 (Surabaya: Evangelical Theological Seminary of Indonesia, 2017), 17.

${ }^{246}$ Philip J. King dan Lawrence E. Stager, Kehidupan Orang Israel Alkitabiah, penerj. Robert Setio dan Atdi Susanto, 429

247 Suhardi, Menekung di Puncak Gunung: Jalan Keselamatan Kejawen (Yogyakarta: Gadjah Mada University Press, 2018), 226. 
Demikian juga seorang yang mati masih berkewajiban berbakti kepada Suksma Sejati ketika berada di dunia orang mati atau kafiruna. ${ }^{248}$

Dari paparan di atas, kita melihat adanya pemahaman yang tidak dapat disejajarkan mengenai dunia orang mati. Dalam Perjanjian Lama manusia yang telah mati terpisah dari Allah dan tidak dapat memuliakan Allah atau melakukan apa-apa lagi. Dalam ajaran aliran Pangestu, manusia yang telah mati masih dapat bertobat dan harus berbakti kepada Yang Maha Kuasa serta ber-reinkarnasi.

Selanjutnya, ada kesamaan kedua konsep tentang absennya ajaran mengenai akses roh orang mati untuk dapat hadir dalam dunia manusia yang masih hidup.

Sebagai abdi Allah, Samuel pastilah hidup sesuai dengan kehendak Allah dan menaati Hukum Tuhan atau sering disebut Taurat. Sebagai umat pilihan Allah, maka kewajiban umat agar dapat menjalankan setiap perintah-Nya. Dari ajaran aliran Pangestu tersebut, jika seseorang sudah menyatu dengan Suksma Sejati maka ada perubahan secara signifikan dalam diri orang tersebut. Tampaklah kebijaksanaan Allah dalam diri orang itu, lalu yang didengarnya adalah perintah Allah, yang dirasakan adalah keadilan Allah, dan yang diciumnya adalah kehadiran Allah. ${ }^{249}$ Jadi Samuel dapat dipandang sudah menyatu dengan Allah sejak ia hidup.

Bagi kalangan Pengestu yang menjadi Kristen, pada kehidupan kekristenan masa kini, Suksma Sejati disejajarkan dengan pribadi Yesus karena Ia adalah Sabda yang telah menjadi manusia. ${ }^{250}$ Dengan bimbingan Suksma Sejati, maka roh suci (orang mati) dapat manunggal dengan Allah. ${ }^{251}$

\section{PENUTUP}

${ }^{248}$ Sularso Sopater, Inti Ajaran Aliran Valentinian dan Inti Ajaran Aliran Pangestu: Suatu Pembandingan, 140.

${ }^{249}$ Harun Hadiwiyono, Kebatinan dan Injil, 88.

${ }^{250}$ Sularso Sopater, Inti Ajaran Aliran Valentinian dan Inti Ajaran Aliran Pangestu: Suatu Pembandingan, 89.

${ }^{251}$ Suhardi, Menekung di Puncak Gunung: Jalan Keselamatan Kejawen, 226. 
Melalui hasil perbandingan dan dialog yang telah penulis lakukan, ada beberapa hal yang dapat penulis simpulkan. Pertama, dalam kerangka pikir Pangestu, dipandang bahwa Samuel telah mati secara sempurna dan bahkan ketika masih hidup sudah manunggal dengan Allah. Oleh karena ia juga setia menjalankan Hukum Tuhan.

Mengenai dunia setelah kematian dalam kedua teks ini, terlihat perbedaanperbedaan yang sangat signifikan, tetapi memiliki kesamaan yaitu roh orang yang sudah mati tidak dapat hadir ke dalam dunia.

Fokus teologi Deuteronomis yang terdapat dalam 1 Sam. 28 menekankan ajaran mengenai Allah yang Esa. Demikian juga dalam ajaran aliran Pangestu menuntun umat agar manunggal kepada Allah yang Tunggal. Jelasnya demikian, "Sesungguhnya Tuhan itu hanya satu yang wajib disembah, tiada Tuhan yang disembah kecuali Allah, dan Allah tempat sesembahan yang sejati."252

Catatan lain adalah ajaran mengenai kematian dalam 1 Samuel 28, tidak dapat sepenuhnya disejajarkan dengan ajaran aliran Pangestu, sebab dalam Pangestu dipercayai bahwa orang yang telah mati dan menyatu dengan Suksma Sejati ia akan menjadi Tuhan kecil. Jika ia meninggal dunia, akan kembali kepada asalnya, yaitu Tuhan dan menjadi Tuhan. ${ }^{253}$ Sedangkan dalam Perjanjian Lama dipercayai bahwa orang yang mati akan berada di sheol. Kata ini diambil dari bahasa Ibrani yang berarti dunia bawah, dibayangkan bahwa mereka yang sudah mati berkumpul (Ams. 9:18). ${ }^{254}$

Hal demikian juga berlaku atas Samuel dan menjadi jawaban atas misteri di Endor, bahwa seseorang yang sudah dalam dunia bawah atau sheol tidak dapat dipanggil kembali ke dunia. Hanya Allah yang dapat hadir di mana Ia mau.

${ }^{252}$ Harun Hadiwiyono, Kebatinan dan Injil, 66.

${ }^{253}$ Harun Hadiwiyono, Kebatinan dan Injil, 97.

${ }^{254}$ W.R.F. Browning, Kamus Alkitab, A Dictionary of the Bible: Panduan Dasar ke dalam Kitab-kitab, Tema, Tempat, Tokoh, dan Istilah Alkitabiah, penerj. Liem Khiem Yang dan Bambang Subandrijo (Jakarta: BPK Gunung Mulia, 2015), 429. 


\section{DAFTAR PUSTAKA}

Bergant, Dianne dan Robert J. Karris. Tafsir Alkitab Perjanjian Lama. Diterjemahkan oleh A.S. Hadiwijaya. Yogyakarta: Kanisius, 2002.

Blommendal, J. Pengantar Kepada Perjanjian Lama. Diterjemahkan oleh P.S. Naipospos. Jakarta: BPK Gunung Mulia, 2013.

Browning, W.R.F. Kamus Alkitab. A Dictionary of the Bible: Panduan Dasar ke dalam Kitabkitab. Tema, Tempat, Tokoh, dan Istilah Alkitabiah. Diterjemahkan oleh Liem Khiem Yang dan Bambang Subandrijo. Jakarta: BPK Gunung Mulia, 2015.

Faot, Agustinus, Jonathan Octavianus, dan Juanda. Kematian Bukan Akhir dari Segalanya. Jurnal Kerruso Vol. 2, No. 2. Surabaya: Evagelical Theological Seminary of Indonesia, 2017

Gertz, Jan Christian dkk. Purwa Pustaka: Eksplorasi ke dalam Kitab-kitab Perjanjian Lama dan Deuterokanonika. Diterjemahkan oleh Robert Setio dan Atdi Susanto. Jakarta: BPK Gunung Mulia, 2017.

Hadiwiyono, Harun. Kebatinan dan Injil. Jakarta: BPK Gunung Mulia, 1987.

Hinson, David F. Sejarah Israel: Pada Zaman Alkitab. Diterjemahkan oleh Marthinus Theodorus Mawene Jakarta: BPK Gunung Mulia, 2015.

https://www.academia.edu/36332977/KEJAWEN, diakses 24 Agustus 2020.

Jong, S. De. Salah Satu Sikap Hidup Orang Jawa. Yogyakarta: Kanisius, 1976.

King, Philip J. dan Lawrence E. Stager. Kehidupan Orang Israel Alkitabiah. Diterjemahkan oleh Robert Setio dan Atdi Susanto. Jakarta: BPK Gunung Mulia, 2012.

Ludji, Barnabas. Pemahaman Dasar Perjanjian Lama: Untuk Studi Kritis. Jilid 1. Bandung: Bina Media Informasi, 2009.

Muryana. Dialog Interreligius - Kultural dan Civil Religion Studi atas Pagutuban Ngesti Tunggal. Jurnal ESENSIA, Vol. XIV No. 2. Yogyakarta: UIN Sunan Kalijaga, 2013.

Noth, Marthin. The Deuteronomistic History. Journal for the Study of the Old Testament Supplement Series 15. Second Edition. Sheffield: JSOT Press, 1981.

Preuss, Horst Dietrich. Old Testament Teology Vol. 1, The Old Testament Library. Diedit oleh James L. Mays. Carol A. Newsom dan David L. Petersen. Louisville: Westminster John Knox Press, 1995. 
Sopater, Sularso. Inti Ajaran Aliran Valentinian \& Inti Ajaran Aliran Pangestu: Suatu Perbandingan. Bandung: Badan Media Informasi, 2011.

Subagya, Rahmat. Kepercayaan Kebatinan Kerohanian Kejiwaan dan Agama. Yogyakarta: Kanisius, 1995.

Suhardi. Menekung di Puncak Gunung: Jalan Keselamatan Kejawen. Yogyakarta: Gadjah Mada University Press, 2018.

Tentang Penulis:

Alentinus Yonathan menyelesaikan studi teologi (S1) di STT Cipanas, Jawa Barat. Saat ini dalam proses kependetaan di Sinode GKSBS Lampung; dapat dihubungi melalui email:

Alentinus.Yonathan@gmail.com. 